\title{
RAZÕES E REFLEXOS DA GRAVIDEZ NA ADOLESCÊNCIA: NARRATIVAS DOS MEMBROS DA FAMÍLIA
}

\author{
Reasons and consequences of adolescent pregnancy: \\ testimonies of family members \\ Embarazo en la adolescencia: razions y reflejo en las familia \\ narrativas de los miembros de la familia
}

Luiza Akiko Komura Hoga ${ }^{1}$

Ana Luiza Vilella Borges ${ }^{2}$

Luciana Magnoni Reberte ${ }^{3}$

\section{RESUMO}

Em inúmeros países, a gravidez na adolescência constitui problema emergente. Este artigo descreve as razões que levam à sua ocorrência e seus reflexos sobre a família, segundo o olhar de seus próprios membros. A pesquisa, de abordagem qualitativa, desenvolveu o método da análise de narrativa para entrevistar 19 pessoas que viveram a experiência da gravidez na adolescência no contexto da família. Das narrativas emergiram duas categorias descritivas: a) As razões da gravidez na adolescência e b) Os reflexos da gravidez sobre a família e a vida das adolescentes. A gravidez na adolescência provocou impacto na dinâmica familiar, e suas características dependeram das crenças e valores prevalentes em cada família. Dados sistematizados a este respeito devem ser obtidos para prover uma assistência apropriada às demandas das adolescentes e dos membros de sua família.

Palavras-chave: Gravidez na Adolescência. Família. Assistência à Saúde.

\begin{abstract}
Adolescent pregnancy is a growing public health problem that affects several countries. This article describes the factors that contribute to teenage pregnancy and the impact it has on the family - from the point of view of the family members. The present research applied the qualitative approach and was developed using the method of narrative analysis to interview 19 individuals who experienced pregnancy during adolescence in a family context. Two descriptive categories emerged from these testimonies. a) The factors that contribute to adolescent pregnancy b) Consequences of pregnancy on the family and impact on the life of the adolescent. Pregnancy during adolescence has an impact on the family dynamics, and its characteristics can vary depending on the beliefs and values that exist in each family. Systematized data associated to this problem should be obtained in order to provide adequate attention to the demands of adolescents and their family members
\end{abstract}

Key words: Pregnancy in Adolescence. Family. Delivery of Health Care.

\section{Resumen}

El embarazo de la adolescencia constituye un problema de salud pública emergente en numerosos países. Este artículo describe las causas que propician el embarazo en la adolescencia y el reflejo que tiene en la familia bejo la perspectiva de sus miembros. El método de investigación utilizado fue el análisis narrativo. Fueron entrevistadas 19 personas que vivenciaron la experiencia del embarazo durante la adolescencia dentro del contexto familiar. A partir de los relatos surgieron las categorías descriptivas: a) Las causas del embarazo en la adolescencia, b) Los reflejos del embarazo sobre la familia y la vida de las adolescentes. El embarazo en la adolescencia provocó impacto en la dinámica familiar y y las características dependieron de las creencias y de los valores que prevalecían en cada familia. . Los profesionales deben obtener datos sistematizados relacionados con cada familia para ofrecer asistencia adecuada de acuerdo con las demandas que son particulares a cada uno de ellos.

Palavras Clave: Embarazo en Adolescencia. Familia. Prestación de Atención de Salud.

'Livre-docente em Enfermagem. Professora Associada do Departamento de Enfermagem Materno-Infantil da Escola de Enfermagem da Universidade de São Paulo (EEUSP). Brasil. E-mail: kikatuca@usp.br, ²Doutora em Saúde Pública. Professora do Departamento de Enfermagem em Saúde Coletiva da Escola de Enfermagem da Universidade de São Paulo (EEUSP). Brasil. E-mail: alvilela@usp.br , ${ }^{3}$ Mestre em Enfermagem. Aluna de Doutorado da Escola de Enfermagem da USP. Bolsista CAPES. Brasil. E-mail: lureberte@usp.br 
Razões da gravidez na adolescência

Hoga LAK, Borges ALV, Reberte LM

\section{INTRODUCÃO}

No Brasil, em 2004, foram registrados mais de três milhões de nascimentos dos quais $21,9 \%$ correspondiam a mães com idade entre 10 e 19 anos. ${ }^{1}$ A gravidez na adolescência ocorre de forma bastante distinta não apenas nas diversas regiões do País, mas também nos vários grupos sociais. Um estudo brasileiro demonstrou que a porcentagem de adolescentes que tinha engravidado pelo menos uma vez na vida variou entre $36,9 \%$ na região Nordeste e $12,2 \%$ na região Sul. ${ }^{2} \mathrm{~A}$ Pesquisa Nacional de Demografia e Saúde, conduzida em 2006, mostrou uma relação inversa entre o nível de escolaridade e a ocorrência de gravidez na adolescência que declinou de $40,7 \%$ entre as adolescentes não letradas para praticamente zero entre as que tinham 12 ou mais anos de estudo. ${ }^{3}$

Apesar de a gravidez na adolescência ocorrer com maior frequência nos grupos mais empobrecidos, não se pode negar que o fenômeno acontece em todos os estratos populacionais, porém suas consequências podem ser mais negativas para adolescentes cuja inserção social restringe 0 acesso a bens materiais e imateriais.

Ainda que a ocorrência de uma gravidez na adolescênciajá tenha sido considerada um evento comum e até mesmo esperado em décadas passadas, atualmente, é concebida como problema de saúde pública, ${ }^{4}$ o que tem mobilizado tanto a sociedade civil como os trabalhadores e pesquisadores da área da saúde a conhecer as causas de sua ocorrência. Assim, persiste uma concepção generalizada que a relaciona exclusivamente à pobreza e à exclusão social, ora tidas como causas, ora como consequências da gravidez na adolescência.

Por sua vez, investigações conduzidas com mulheres que vivenciaram a experiência da gravidez na adolescência têm observado que a maternidade pode se constituir em um projeto de vida, que sela a entrada da mulher adolescente ao mundo adulto e o seu reconhecimento pela família e rede social. ${ }^{5}$

É inegável que os determinantes da gravidez na adolescência envolvam elementos sociais extremamente complexos e difíceis de serem equacionados, dentre os quais a inserção social da família, aspecto que está associado às vulnerabilidades no campo da saúde sexual e reprodutiva. ${ }^{6}$

Mesmo que as razões que levam uma adolescente a engravidar sejam bem exploradas pelos pesquisadores e mídia, em geral, pouco se sabe sobre o que pensam os membros da família da adolescente que engravida a respeito das razões dessa ocorrência. Pressupõe-se que a família reage de modo singular diante deste fenômeno, não apenas porque vivencia íntima e intensamente o momento em que ocorre a gravidez com um de seus membros adolescentes, mas também porque contribui na trajetória das pessoas envolvidas. Neste estudo, considerou-se que tal singularidade precisa ser conhecida para possibilitar o desenvolvimento de ações espećficas, pois é crucial que os profissionais estabeleçam relação entre as necessidades que emanam do contexto social, da família e da própria adolescente grávida e a assistência a ser prestada. ${ }^{7}$
Esc Anna Nery Rev Enferm 2010 jan-mar; 14 (1): 151 -57

Este estudo buscou conhecer a perspectiva dos membros da família das adolescentes, pois eles influenciam as decisões e ações na esfera da gravidez na adolescência, contribuindo para que seja superada a visão da gravidez na adolescência apenas como um problema a ser evitado. Assim, o objetivo deste artigo foi descrever as razões que levam à ocorrência da gravidez na adolescência e seus reflexos sobre a família segundo o olhar de seus próprios membros.

\section{MÉTODO}

0 método da análise da narrativa foi utilizado em razão do caráter naturalístico ${ }^{8}$ desta pesquisa. A essência deste método consiste no acesso à experiência primária, tal como representada pela pessoa que a vivencia. As cinco etapas previstas neste método foram desenvolvidas.

A primeira etapa, de propor a pesquisa, teve a finalidade de acessar a experiência de pessoas que tinham compartilhado a experiência da gravidez na adolescência no contexto da família.

$\mathrm{Na}$ segunda etapa, de permitir o relato da experiência, foram feitos contatos com os membros da família de adolescentes grávidas ou mães, que serão denominados neste artigo como colaboradores. A família foi considerada como contexto da pesquisa porque os fatores nela envolvidos influenciam significativamente a vivência da experiência. ${ }^{9} \mathrm{Ao}$ realizar pesquisa com famílias, a colaboração pode ser solicitada a apenas um de seus membros ou ao conjunto de pessoas que as compõem. ${ }^{10}$ Ser membro da família com relação de consanguinidade e estar morando com a adolescente no momento da ocorrência da gravidez foram os critérios de inclusão adotados nesta pesquisa.

0 primeiro colaborador foi uma pessoa conhecida de um dos pesquisadores. Ele morava em um bairro periférico de uma cidade grande localizada no Estado de São Paulo, no qual viviam, predominantemente, famílias de baixa renda. Realizar pesquisa em população com esta característica tem importância social porque a compreensão dos fatores dinâmicos, complexos e estruturais que envolvem uma dada questão constitui a primeira etapa do desenvolvimento de políticas públicas. ${ }^{11}$ Ao término da entrevista, solicitou-se a apresentação de um vizinho ou conhecido que se enquadrasse nos critérios de inclusão, e semelhante medida foi seguida até a incorporação do último colaborador. Todos foram informados da proposta da pesquisa e solicitados a participar, e não houve recusas a esse respeito.

Foram entrevistadas pessoas que desempenhavam diferentes papéis familiares; esta medida foi importante para captar variadas visões a respeito do fenômeno. Este cuidado possibilitou retratar o sistema familiar que integra outros sistemas com maior abrangência. ${ }^{10}$ Por meio da realização das entrevistas foi possível acessar as representações pessoais a respeito da experiência. A seguinte pergunta introdutória foi feita: "Fale-me de seu olhar a respeito da gravidez na adolescência, e o que isto representou para você e sua família?". Questões adicionais foram feitas para aprofundar tópicos 
abordados superficialmente. A atitude de escuta ativa foi mantida com o intuito de priorizar o ponto de vista do colaborador.

Seus dados pessoais, os relativos à estrutura familiar e à situação conjugal das adolescentes foram obtidos antes do início das entrevistas. Quinze depoimentos foram obtidos em um recinto da residência do colaborador e quatro no local de trabalho, onde apenas o pesquisador e o entrevistado estavam presentes. As entrevistas foram iniciadas em novembro de 2005 e encerradas em janeiro de 2007 e tiveram duração entre 20 e 60 minutos. 0 critério adotado para encerrar a inclusão de novos colaboradores foi a repetição contínua dos dados, percebida a partir da $15^{\text {a }}$ entrevista. Foram incluídas 19 pessoas para que a saturação teórica dos dados estivesse garantida.

A terceira etapa, da transcrição da experiência, foi realizada, mediante a transformação da entrevista gravada para a forma escrita. As características individuais de expressão foram preservadas, e os erros gramaticais, corrigidos.

Na quarta etapa, de análise da experiência, foram seguidos os pressupostos de eminentes pesquisadores que desenvolvem 0 método qualitativo de pesquisa. ${ }^{8,12}$ Suas principais recomendações incluem a necessidade de adotar uma atitude aberta e isenta de preconceitos ou pressuposições diante dos dados. Mediante esta postura, foi feita a análise do conjunto de depoimentos, de forma interpretativa e indutiva, como sugerida pelos autores referidos. Primeiramente, foi realizada uma leitura atenta de cada narrativa, e, nas leituras subsequentes, os significados constantes em cada depoimento foram identificados e uma codificação preliminar foi feita. A realização desse trabalho se assemelhou ao processo de elaboração de uma coreografia, cujo esquema é delineado com certa liberdade, mas garantindo a preservação das principais representações acerca da experiência que emergiam dos depoimentos.

Na quinta etapa, de leitura da experiência, a recorrência das ideias relativas à representação da experiência foi identificada, o que possibilitou concretizar a elaboração das categorias descritivas. Pequenos trechos extraídos das narrativas foram utilizados para exemplificar conteúdos e significados constantes nas categorias descritivas. Esses trechos foram separados por pontos (...), o que indica que cada parte foi extraída de um colaborador distinto. Este recurso foi usado para tornar a descrição da experiência mais próxima da realidade e preservar a perspectiva pessoal dos colaboradores, pois estes dois aspectos são cruciais no desenvolvimento do método de análise da narrativa. ${ }^{8}$

A perspectiva familiar deste estudo implicou a elaboração de genogramas, a fim de conhecer o padrão de interação e melhor caracterizar as famílias estudadas. Ele se constitui em uma representação gráfica da composição familiar e dos relacionamentos básicos e permite, de uma forma rápida e clara, visualizar quais são os membros que constituem a família, tenham eles vínculos consanguíneos ou não, identificando a idade e ocupação de cada pessoa, além de retratar o lugar ocupado por cada um dentro da estrutura familiar. A família foi caracterizada como nuclear quando composta por pai, mãe e filhos e extensa quando incluía outros membros que tenham laços de parentesco. ${ }^{9}$

Esta pesquisa obedeceu ao preconizado na Resolução 196/ 1996 do Conselho Nacional de Saúde. ${ }^{13} 0$ projeto de pesquisa foi aprovado por um comitê credenciado no Conselho Nacional de Ética em Pesquisa, e o seu desenvolvimento foi aprovado. Todos assinaram o Termo de Consentimento Pós-Informação, em que havia explicitação dos direitos dos colaboradores. eram os de mãe (12), pai (3), irmã (2) e irmão (2). Eles tinham entre 23 e 56 anos de idade. Quanto à situação conjugal, quatro eram solteiros; sete, amigados; cinco, casados; dois, separados; e um era viúvo. Houve variação entre nenhum e 15 anos de estudo, e a religião era católica ou evangélica. Todos eram brasileiros natos.

Quanto à situação financeira, dez dependiam dos proventos obtidos por outra pessoa da família e nove obtinham seus próprios recursos. As ocupações das nove pessoas que trabalhavam fora de casa eram: cozinheiro, copeiro, garçom, empregado doméstico, professor de ensino fundamental, funcionário público, faxineira, ajudante geral e vendedora. A renda mensal individual dos colaboradores variou de $\mathrm{R} \$ 550,00$ a $\mathrm{R} \$ 1.500,00$.

0 genograma familiar permitiu a compreensão da composição familiar que revelou que dez colaboradores integravam famílias nucleares e nove, famílias extensas. A quantidade de pessoas por família variou entre três e oito nas famílias nucleares e entre cinco e 13 nas famílias extensas.

A idade das adolescentes no momento da ocorrência da gravidez variou de 14 a 18 anos. A respeito dos reflexos da gravidez sobre a situação marital e de moradia das adolescentes, duas casaram-se e constituíram suas respectivas famílias nucleares, cinco casaram-se e foram morar com os familiares dos maridos, quatro permaneceram solteiras e com o filho e continuaram morando com os pais, e oito casaram-se e, também, continuaram morando com o filho e o marido na casa dos pais.

\section{CATEGORIAS DESCRITIVAS}

\section{As razões da gravidez na adolescência}

A gravidez foi considerada como uma consequência dos problemas pessoais, familiares e socioeconômicos enfrentados pelas adolescentes. Isso refletiu no desejo de ser mãe, cuja condição era vista como uma possibilidade concreta para sair de casa e constituir sua própria família. 0 seguimento desta trajetória levaria à conquista da liberdade e da autonomia que as adolescentes não tinham quando moravam com os pais.

"Ela falava que não via a hora de sair de casa para ter liberdade... Desde os 12 anos ela falava que queria engravidar para ter a própria casa e família" 
Razões da gravidez na adolescência

Hoga LAK, Borges ALV, Reberte LM

Outro ponto levantado consistia na precocidade do namoro, que estava associado à falta de cuidado com a anticoncepção.

"Eu deixei ela namorar muito cedo... minha filha sabia como evitar, não sei como aconteceu a gravidez... decerto ela não tomou o devido cuidado para evitar filho"

As "más companhias" que influenciavam negativamente as adolescentes também foram relatadas como aspectos que contribuíram para a ocorrência da gravidez. As amizades inadequadas eram inevitáveis em razão das características socioeconômicas e estruturais muito precárias do local onde moravam. Os familiares alegaram falta de domínio sobre esta situação e lamentaram a necessidade de conviver continuamente com o problema.

"Foi a má influência das amigas... Esse lugar é muito difícil na questão da educação"

A rebeldia, que foi vista como característica própria da fase da adolescência, também foi mencionada como fator que impulsionou a ocorrência da gravidez. Aventou-se a possibilidade de as adolescentes terem encarado a gravidez como um subterfúgio para causar aborrecimentos à família.

"Ela queria passear e eu não deixei ...Ela era rebelde... Eu orientei mas não adiantou... Ela engravidou porque era rebelde. Até os anticoncepcionais tomou errado ... Ela engravidou de propósito, para provocar e contrariar a família"

A gravidez como um desígnio divino a que os seres humanos estão sujeitos foi narrada. Nas famílias em que predominava esta crença, a notícia da gravidez não trouxe grandes transtornos, e todo seu transcorrer foi permeado pelos sentimentos de louvor e gratidão pela dádiva recebida. Embora tais sentimentos tenham prevalecido, observou-se o sentimento de resignação diante da situação.

"Foi da vontade de Deus... quando é Deus quem manda o filho, aí não tem jeito"

Os colaboradores alegaram que a gravidez ocorreu mesmo apesar das orientações insistentemente fornecidas a respeito dos cuidados necessários para evitá-la. 0 fornecimento dessas orientações foi mencionado por quase todos os colaboradores. Salientou-se que o papel de orientar as adolescentes era desempenhado primordialmente pelas mães.

"Eu falava quase todo dia: filha, tome cuidado para não engravidar. . . Falava: se cuida, filha, gravidez é só depois do casamento"
Esc Anna Nery Rev Enferm 2010 jan-mar; 14 (1): 151 -57

0 costume de atribuir a culpa pela ocorrência da gravidez a algum membro da família foi observado. A responsabilidade por este acontecimento recaía sobre as mães, que eram acusadas de não ter cumprido a contento seu papel como orientadoras nem ter mantido a vigilância necessária em relação ao comportamento das filhas.

"A culpa caiu para o meu lado (mãe) ... meu marido disse: a culpa é sua! Você não vigiou, não orientou"

\section{Os reflexos da gravidez sobre a família e a vida das adolescentes}

A gravidez na adolescência provocou impacto forte e diferenciado sobre as relações entre os membros da família, a dinâmica familiar e a vida das adolescentes.

Os efeitos da gravidez foram vistos apenas pela perspectiva puramente positiva em algumas famílias. Nesses casos, a alegação era de que a presença da criança na família promoveu a paz e a união entre seus membros e contribuiu para melhorar o ambiente familiar, fazendo com que o sentimento de felicidade predominasse.

"Essa criança uniu a família ... Trouxe a paz para a família ... As duas famílias se uniram ... é bom demais. Cuido e amo a criança... Meu neto é nossa felicidade, trouxe paz"

Entretanto, grandes enfrentamentos tiveram de ser superados até que fosse encontrado um consenso a respeito do problema e conquistada a harmonia familiar.

"Depois de muitas brigas conseguimos a paz... No início, deu choque, mas conseguimos chegar a um consenso, ficamos unidos... A criança trouxe alegria"

A ocorrência da gravidez e o consequente nascimento de uma criança na família demandou muitas adaptações, que foram necessárias no aspecto financeiro, no local de moradia e de trabalho. Foram alterações imprescindíveis ao atendimento das novas necessidades e provocaram impacto no cotidiano familiar.

"Foi difícil, mexeu com a estrutura da família ... Reformamos a casa para acomodar a criança"

A elevação do orçamento doméstico demandou o aumento da renda familiar. Para isto, houve a premência de se buscar meios para aumentar os ganhos, e isto fez com que alguns membros da família tenham mudado de emprego ou incorporado novas atividades remuneradas. Outras famílias avaliaram que apenas houve a necessidade de adequar os hábitos de consumo em razão do acréscimo representado pelos gastos demandados pela criança.

"Fiz horas extras para pagar as contas que aumentaram .. Tive que mudar de emprego para 
poder ganhar mais... Tudo ficou muito mais difícil no lado financeiro... Com a chegada da criança, precisamos só acomodar os nossos gastos"

A gravidez e a incorporação do papel materno por parte das adolescentes trouxeram grandes mudanças em suas vidas, sobretudo nas atividades diárias, como o estudo e o trabalho.

"Parou de estudar... Parou de estudar para trabalhar ... Tentou continuar estudando, mas não conseguiu... Estudava e também começou a trabalhar .... Estudava e continuou estudando"

0 advento da maternidade fez com que as adolescentes amadurecessem rápido e precocemente. Isto provocou reflexos imediatos em seus comportamentos. Na percepção dos colaboradores, as adolescentes tornaram-se mais responsáveis em todos os sentidos. Foi percebida, inclusive, uma mudança no que dizia respeito ao semblante que passou a transparecer o ar maternal.

"Ela amadureceu, ficou mais responsável.... Foi notável a mudança no jeito de ser... Ficou com ar de mãe... Passou a ser uma mãe perfeita"

Os familiares perceberam também que a gravidez e a necessidade de assumir o papel materno fizeram com que as adolescentes abandonassem as "más companhias" e a "perdição de rua", pois, caso persistissem, provocariam danos maiores em suas vidas. Notaram também que o comportamento mudou para melhor, pois, até então, era desvirtuado e passou a ser exemplar com o advento da gravidez e da maternidade.

"Ela colocou a cabeça no lugar... Largou as amizades ruins... Saiu da perdição da rua... Hoje é uma moça exemplar"

\section{DISCUSSÃO}

As famílias, cujos membros vivenciaram uma gravidez na adolescência não apontaram aspectos de ordem estrutural pobreza e exclusão familiar - como razões que levaram as adolescentes a engravidar, mas, antes de tudo, enfatizaram razões de natureza pessoal. A falta de liberdade e a consequente ausência de autonomia foram consideradas como causas indiretas da ocorrência da gravidez na adolescência. 0 fato demonstra que os familiares não conheciam, não respeitaram ou não tinham condições de prover o conjunto das necessidades das adolescentes, mostrando um delicado jogo no âmbito das relações parentais entre dar mais autonomia aos filhos nas questões de amizades e saídas noturnas ou adotar uma postura mais rígida e controladora. Ressalta-se que tanto a rigidez dos pais quanto a flexibilidade no trato com as filhas foram simultaneamente apontadas como causas da gravidez.
Em uma investigação sobre sexualidade de adolescentes, revelou-se que os pais compreendem a sexualidade como sinônimo de ato sexual, fazendo com que a abordagem deles em relação às filhas fosse caracterizada por proibição do sexo, ausência de diálogo ou ameaças, gerando dificuldades para o estabelecimento de uma comunicação efetiva sobre sexualidade na família. ${ }^{14}$

A precocidade do namoro foi mencionada como uma das razões da ocorrência da gravidez. Estudos mostram que 0 namoro está fortemente associado ao início da vida sexual na adolescência, sobretudo por ser o relacionamento afetivo e amoroso mais típico da adolescência, assim como o "ficar". ${ }^{15} \mathrm{E}$ possível considerar que o namoro necessitaria estar entre os tópicos abordados nas intervenções realizadas com os adolescentes justamente por se constituir em um espaço de exercício das relações entre homens e mulheres que sejam mais igualitárias ou hierarquizadas, podendo ser transpostas as atitudes e práticas sexuais e contraceptivas.

Em relação à anticoncepção, os entrevistados enfatizaram que as adolescentes tinham amplo conhecimento sobre a questão, mas mesmo assim engravidaram. Faz parte do imaginário social acreditar que o simples acesso à informação sobre anticoncepção seria suficiente para garantir práticas contraceptivas consistentes. 0 descompasso entre 0 conhecimento e o comportamento no campo da contracepção já vem sendo discutido ${ }^{16}$ e pode ser explicado pelo fato de que a contracepção não é uma prática simplesmente racional, mas, sobretudo, relacional e subjetiva, ou seja, é determinada pelo tipo de relação afetivo-amorosa que se dá entre o par, tanto quanto pelas aspirações dos sujeitos.

A má companhia foi indicada como um problema que interfere negativamente na vida das adolescentes. Neste aspecto, importa reconhecer a necessidade da gregária e do pertencimento a grupos típicos desta fase da vida. Além disso, nos momentos de interação com os pares, os adolescentes sentem-se pressionados a incorporar comportamentos alinhados ao grupo, compartilhar visões e seguir regras de conduta cujo conjunto impulsiona-os à adoção de atitudes até mesmo contrárias às orientações recebidas na família e na escola. Isso também pode ser entendido como a negação do domínio parental, na busca de uma declaração de autonomia e individualidade. ${ }^{17}$

A ocorrência da gravidez foi também atribuída a um "desígnio de Deus" ao qual o ser humano deve se submeter. Esta concepção sugere que nada poderia ser feito para evitar a gravidez, indicando que os profissionais devem ter conhecimentos a respeito das crenças e valores das várias vertentes religiosas e dos modos de vivenciar a espiritualidade, para estar capacitado a desenvolver um cuidado significativo deste ponto de vista. Nesse aspecto, considera-se fundamental que os profissionais de saúde integrem as dimensões científica, religiosa e cultural em sua prática clínica. 
Razões da gravidez na adolescência

Hoga LAK, Borges ALV, Reberte LM

No desenvolvimento de trabalhos com as famílias, avaliase a importância de considerar que a identidade, inclusive a religiosa e a cultural, é necessariamente uma construção a ser desvendada. Na sua análise, não é possível decidir se as tradições familiares e culturais se tratam de um peso ou de um avanço. Importa, sobretudo, desvendar como os elementos culturais são processados, quem os processa e por que os processa. ${ }^{18}$ Acredita-se que os profissionais de saúde devem estar atentos a estas questões e propiciar reflexões a este respeito durante as atividades assistenciais e educativas que desenvolve.

Houve a tendência de culpar as mães pela ocorrência da gravidez. Por sua vez, muitas delas alegaram que a gravidez aconteceu apesar das insistentes orientações dadas às adolescentes. Algumas mães que não chegaram a fornecer orientações às suas filhas justificaram que a escola e os meios

\section{CONCLUSÃO}

Neste estudo, tornou-se evidente que a família possui um papel importante na compreensão das causas da gravidez na adolescência, que é explicada de múltiplas formas, não só pela própria mulher adolescente, mas também pela família e pela rede de relações sociais, a depender das crenças religiosas e das expectativas sobre o futuro educacional e profissional de adolescentes.

Percebeu-se que os membros da família se sentiram corresponsáveis pela ocorrência da gravidez. A família esperava ter controle sobre a conduta da adolescente, mas as dificuldades na relação familiar limitaram as possibilidades de um diálogo mais amplo a respeito da iniciação sexual e vivência da sexualidade. Por outro lado, a crença religiosa fez com que a família acreditasse que a ocorrência da gravidez não estava sob seu controle, pois não poderia alterar o destino traçado por Deus para a adolescente.

Desta forma, a gravidez também é vivenciada de maneiras distintas, implicando na redefinição das relações familiares. A de comunicação se encarregavam desse trabalho, não levando em consideração que a orientação sexual é determinada em conjunto entre todas as agências de socialização presentes na vida dos adolescentes.

0 comportamento familiar apenas reforça os dados de uma pesquisa que demonstrou que apenas $20 \%$ dos adolescentes recorreram aos pais para sanar suas dúvidas no que diz respeito à sexualidade na adolescência. ${ }^{19} \mathrm{Em}$ oficinas realizadas com estudantes do ensino médio, revelou-se que este tema é um campo de conflitos entre pais e filhos. Os poucos adolescentes que procuraram os pais para orientação sexual o fizeram com restrições, pois os assuntos de maior intimidade eram reservados aos amigos. ${ }^{20}$ Estes são indícios de que todos os membros da rede de relações dos adolescentes necessitam ser agregados ao trabalho de promoção da saúde sexual e reprodutiva desse segmento.

chegada de um novo membro da família representa a superação de dificuldades financeiras e conflitos familiares. Além disso, ao assumir um novo papel perante a família, a adolescente passa a ser vista com maior admiração e respeito. Nesse sentido, a gravidez nem sempre é vista como um fato essencialmente negativo, pois a família une-se para minimizar as consequências indesejáveis desse evento e torná-lo positivo tanto à família como aos jovens pais.

Este conjunto, associado aos fatores do contexto social e cultural, fundamenta os comportamentos dos membros da família diante da adolescente grávida ou mãe. Promover uma assistência significativa do ponto de vista dos receptores do cuidado à saúde, neste caso os membros da familia diretamente envolvidos com a gravidez na adolescência, foi a proposta de realização desta pesquisa. Por meio dela, buscou-se contribuir para a adoção de uma postura ética diante da adolescente grávida e sua família e, assim, promover a qualidade das relações familiares, que é vital para o pleno desempenho do papel materno na adolescência.

\section{REFERÊNCIAS}

1. Ministério da Saúde (BR). Secretaria de Vigilância em Saúde, Departamento de Análise de Situação em Saúde. Saúde Brasil 2006. Brasília (DF); 2006.

2. Rede Feminista de Saúde. Adolescentes saúde sexual e saúde reprodutiva: dossiê [homepage na internet]. 2004 [citado 10 jan 2009]. Disponível em: http://www.redesaude.org.br/

3. Ministério da Saúde (BR). Secretaria de Ciência, Tecnologia e Insumos Estratégicos. Departamento de Ciência e Tecnologia. Pesquisa Nacional de Demografia e Saúde da Criança e da Mulher-PNDS: 2006. Brasília (DF); 2008

4. Chalem E, Mitsuhiro SS, Ferri CP, Barros MCM, Guinsburg R, Laranjeira R. Gravidez na adolescência: perfil sócio-demográfico e comportamental de uma população da periferia de São Paulo, Brasil. Cad Saude Publica 2007 jan; 23(1): 177-78.

5. Carvalho JEC. How can a child be a mother? Discourse on teenage pregnancy in a Brazilian favela. Cult Health Sex 2007; 9(2): 109-20.

6. Berquó E, Cavenaghi S. Mapeamento sócio-econômico e demográfico dos regimes de fecundidade no Brasil e variação entre 1991 e 2000. In: Anais do 14 Encontro da Associação Brasileira de Estudos Populacionais 2004 set 20-24; Caxambu (MG), Brasil. Belo Horizonte(MG): ABEP 2004. p.1-18.

7. Frota DAL, Marcopito LF. Amamentacäo entre mães adolescentes e não-adolescentes. Rev Saude Publica 2004 fev; 38(1): 85-92.

8. Riessman CK. Narrative analysis: qualitative research methods. London(UK): Sage; 1993.

9. Wright LM, Leahey M. Enfermeiras e famílias - um guia para avaliação e intervenção na família. Tradução de Silvia M. Spada. $3^{\text {a }}$ ed. São Paulo (SP): Roca; 2002. 
10. Lynn MR. Who is the "Family" in family research? J Pediatric Nurs 1995; 10(3):189-91.

11. Shepard MP, Mahon MM. Vulnerable families: research findings and methodological challenges. J Fam Nurs 2002; 8(4): 309-14.

12. Morse JM. Designing funded qualitative research. In: Denzin NK, Lincoln YS. Strategies of qualitative inquiry. Thousand Oaks(CA): Sage; 1998. p. 56-85.

13. Ministério da Saúde (BR). Conselho Nacional de Saúde. Resolução $n^{\circ} 196$, de 10 de outubro de 1996. Diretrizes e normas regulamentadoras de pesquisas envolvendo seres humanos. Inf Epidemiol SUS 1996; 5 (2 supl 3): 13-41.

14. Beserra EP, Pinheiro PNC, Barroso MGT. Ação educativa do enfermeiro na prevenção de doenças sexualmente transmissíveis: uma investigação a partir das adolescentes Esc Anna Nery Rev Enferm 2008 set; $12(3):$ : $22-28$

15. Borges ALV, Latorre MRDO, Schor N. Fatores associados ao início da vida sexual de adolescentes matriculados em uma unidade de saúde da família da zona leste do município de São Paulo, Brasil. Cad Saude Publica 2007 jul; 23(7): 1583-94.

16. Almeida MCC, Aquino EML, Gaffikin L, Magnani RJ. Uso de contracepção por adolescentes de escolas públicas na Bahia. Rev Saude Publica 2003 out; 37(5): 566-75.

17. Scott RP. Quase adulta, quase velha: por que antecipar as fases do ciclo vital? Interface - comunicação, saude educação. 2001 fev; 5(8): 61-2

18. Monteiro P. 0 problema da cultura da igreja católica contemporânea. Estud Av 1995; 9(25): 229-48.

19. Borges ALV, Nichiata LYI, Schor N. Conversando sobre sexo: a rede sociofamiliar como base de promoção da saúde sexual e reprodutiva de adolescentes. Rev Latino-am Enfermagem 2006 maio/ jun;14(3): 422-27.

20. Soares SM, Amaral MA, Silva LB, Silva PAB. Oficinas sobre sexualidade na adolescência: revelando vozes, desvelando olhares de estudantes do ensino médio. Esc Anna Nery Rev Enferm 2008 set; 12 (3): 485-91 